\title{
The BCR-ABL1 Inhibitors Imatinib and Ponatinib Decrease Plasma Cholesterol and Atherosclerosis, and Nilotinib and Ponatinib Activate Coagulation in a Translational Mouse Model
}

\section{OPEN ACCESS}

Edited by:

Klaus T. Preissner,

Justus Liebig Universität Gießen,

Germany

Reviewed by:

Miguel Carracedo,

Karolinska Institutet (KI), Sweden

Cécile Vindis,

INSERM U1048 Institut des Maladies

Métaboliques et Cardiovasculaires,

France

*Correspondence:

Marianne G. Pouwer

marianne.pouwer@tno.n

Specialty section:

This article was submitted to

Atherosclerosis and

Vascular Medicine,

a section of the journal

Frontiers in Cardiovascular Medicine

Received: 03 January 2018

Accepted: 10 May 2018

Published: 12 June 2018

Citation:

Pouwer MG, Pieterman EJ, Verschuren L, Caspers MPM, Kluft C, Garcia RA, Aman J, Jukema JW and

Princen HMG

(2018) The BCR-ABL1 Inhibitors Imatinib and Ponatinib Decrease

Plasma Cholesterol and

Atherosclerosis, and Nilotinib and Ponatinib Activate Coagulation in a

Translational Mouse Model.

Front. Cardiovasc. Med. 5:55.

doi: 10.3389/fCvm.2018.00055

\begin{abstract}
Marianne G. Pouwer ${ }^{1,2 *}$, Elsbet J. Pieterman ${ }^{1}$, Lars Verschuren ${ }^{3}$, Martien P. M. Caspers ${ }^{3}$, Cornelis Kluft ${ }^{4}$, Ricardo A. Garcia ${ }^{5}$, Jurjan Aman ${ }^{6}$, J. Wouter Jukema ${ }^{2}$ and Hans M. G. Princen ${ }^{1}$

${ }^{1}$ Metabolic Health Research, Gaubius Laboratory, The Netherlands Organization of Applied Scientific Research (TNO), Leiden, Netherlands, ${ }^{2}$ Department of Cardiology, Leiden University Medical Center, Leiden, Netherlands, ${ }^{3}$ Microbiology and Systems Biology, The Netherlands Organization of Applied Scientific Research (TNO), Zeist, Netherlands, ${ }^{4}$ Good Biomarker Sciences, Leiden, Netherlands, ${ }^{5}$ Cardiovascular Drug Discovery, Bristol-Meyers Squibb, New York, United States, ${ }^{6}$ Departments of Physiology and Pulmonary Diseases, VU University Medical Center, Amsterdam, Netherlands
\end{abstract}

Treatment with the second and third generation BCR-ABL1 tyrosine kinase inhibitors (TKIs) increases cardiovascular risk in chronic myeloid leukemia $(\mathrm{CML})$ patients. We investigated the vascular adverse effects of three generations of TKIs in a translational model for atherosclerosis, the APOE ${ }^{\star}$ 3Leiden.CETP mouse. Mice were treated for sixteen weeks with imatinib (150 $\mathrm{mg} / \mathrm{kg}$ BID), nilotinib (10 and $30 \mathrm{mg} / \mathrm{kg}$ QD) or ponatinib (3 and $10 \mathrm{mg} / \mathrm{kg} \mathrm{QD}$ ), giving similar drug exposures as in CML-patients. Cardiovascular risk factors were analyzed longitudinally, and histopathological analysis of atherosclerosis and transcriptome analysis of the liver was performed. Imatinib and ponatinib decreased plasma cholesterol (imatinib, $-69 \%, p$ $<0.001$; ponatinib $3 \mathrm{mg} / \mathrm{kg},-37 \%, p<0.001$; ponatinib $10 \mathrm{mg} / \mathrm{kg}-44 \%, p<0.001$ ) and atherosclerotic lesion area (imatinib, $-78 \%, p<0.001$; ponatinib $3 \mathrm{mg} / \mathrm{kg},-52 \%, p=0.002$; ponatinib $10 \mathrm{mg} / \mathrm{kg},-48 \%, p=0.006)$, which were not affected by nilotinib. In addition, imatinib increased plaque stability. Gene expression and pathway analysis demonstrated that ponatinib enhanced the mRNA expression of coagulation factors of both the contact activation (intrinsic) and tissue factor (extrinsic) pathways. In line with this, ponatinib enhanced plasma levels of FVII, whereas nilotinib increased plasma FVIla activity. While imatinib showed a beneficial cardiovascular risk profile, nilotinib and ponatinib increased the cardiovascular risk through induction of a pro-thrombotic state.

Keywords: atherosclerosis, animal model cardiovascular disease, lipids and lipoprotein metabolism, coagulation/ thrombosis, cholesterol, chronic myeloid leukemia, cardiovascular side effects

Abbreviations: ALT, alanine transaminase; AST, aspartate transaminase; BAL, broncho-alveolar lavage; BID, twice a day; CML, chronic myeloid leukemia; DEGs, differentially expressed genes; HPTLC, High-performance thin-layer chromatography; MCP-1, monocyte chemoattractant protein-1; PAOD, progressive arterial occlusive disease; PBMCs, peripheral blood mononuclear cells; PK, pharmacokinetic; QD, once daily; SAA, serum amyloid A; TC, total cholesterol; TG, triglycerides; TKIs, tyrosine kinase inhibitors; VAEs, vascular adverse effects. 


\section{INTRODUCTION}

Chronic myeloid leukemia (CML) is a myeloproliferative neoplasm caused by a translocation of the chromosomes 9 and 22 that results in formation of the Bcr-Abl1 oncogene (1) and a constitutively active c-Abl kinase domain, which drives uncontrolled cell growth and tumorigenesis.

Patients with CML are treated with specific tyrosine kinase inhibitors (TKIs). The first-line TKI imatinib is widely used and has proven to be successful in the treatment of CML. However, relapses are seen in up to $17 \%$ of patients treated with imatinib (2) due to amplification and mutations in the Bcr-Abll gene (3) that lead to imatinib resistance. The second and third generation TKIs, nilotinib and ponatinib among others, are effective against these mutations (3), and promising results have been found in relapsed patients (4). Unfortunately, side effects have been reported in patients receiving these TKIs including myocardial infarction and progressive arterial occlusive disease (PAOD) (57). As a result, ponatinib was temporarily removed from the US market, and was later reintroduced for the treatment of patients with T315I-positive CML or those in whom no other TKI was indicated.

Since the first reports of vascular adverse effects (VAEs), many authors related the adverse effects of TKI treatment to atherosclerosis and abnormal platelet function $(4,7-9)$. However, it is still unclear whether the side effects are caused by enhanced vascular inflammation and endothelial dysfunction, atherosclerosis development, increased thrombotic activity per se, or a combination of these processes. Furthermore, the underlying disease has been reported to affect metabolic parameters (10) and coagulation (11), which may interfere with the onset of the side-effects upon treatment. Therefore, to elucidate the role of TKI treatment on VAE's independently of a background of leukemia, we performed a detailed experimental study in healthy pro-atherogenic mice. The aim of this study was to assess the (cardio)vascular side effects of the second and third generation of TKIs, nilotinib and ponatinib, and to compare their effects to the first generation TKI imatinib.

In this study, we used the $\mathrm{APOE}^{\star} 3$ Leiden.CETP mouse as a well-established model for dyslipidemia and atherosclerosis, with a human-like lipoprotein metabolism and atherosclerosis development (See Supplemental material online for more detailed information on the background of the $\mathrm{APOE}^{\star} 3$ Leiden.CETP mice and their response to hypolipidemic drugs; Data Sheet S1). These mice show a human-like response to all lipid-modulating interventions that are being used in the clinic (12-18) and have been used previously to investigate the underlying mechanism of cardiovascular safety issues (19).

We found that imatinib and ponatinib decreased plasma cholesterol, which was associated with decreased atherosclerosis development. Gene expression and pathway analysis demonstrated adverse alterations in genes involved in coagulation which were in line with increased plasma levels of FVII and FVIIa by ponatinib and nilotinib respectively, pointing towards thrombosis instead of atherosclerosis as inducer of the VAEs.

\section{MATERIALS AND METHODS}

\section{Animals}

Female APOE ${ }^{3}$ Leiden.CETP transgenic mice (9 to 14 weeks of age) from the SPF breeding stock at TNO-Metabolic Health Research (TNO-Leiden) were used in this study. Females were used because they are more responsive to dietary cholesterol and fat than males. $\mathrm{APOE}^{\star} 3$ Leiden females have a higher VLDL production (20) than males resulting in higher plasma total cholesterol (TC) and triglyceride (TG) levels and more pronounced development of atherosclerosis $(21,22)$. During the study, mice were housed under standard conditions with a $12 \mathrm{~h}$ light-dark cycle and had free access to food and water. Body weight, food intake and clinical signs of behavior were monitored regularly during the study. Animal experiments were approved by the Institutional Animal Care and Use Committee of The Netherlands Organization for Applied Research under registration number 3557.

\section{Experimental Design and Analyses}

Mice were fed a semi-synthetic diet, containing saturated fat from $15 \%(\mathrm{w} / \mathrm{w})$ cacao butter and $0.15 \%$ cholesterol (Westerntype diet [WTD]; Hope Farms, Woerden, The Netherlands). All studies started after a run-in period of 3 weeks on WTD, which is designated as $\mathrm{T}=0$ weeks/baseline, after which mice were matched into groups based on body weight, total cholesterol, plasma triglycerides and age. For the pharmacokinetic (PK) study, mice were randomized in 3 groups ( $n=9$ per group) and received a single oral gavage with imatinib $(100 \mathrm{mg} / \mathrm{kg})$, nilotinib $(50 \mathrm{mg} / \mathrm{kg})$ or ponatinib $(5 \mathrm{mg} / \mathrm{kg})$. At $0.5,1$ and $2 \mathrm{~h}$ after oral gavage, blood was sampled from 3 mice per group per time point, and at 4, 7 and $24 \mathrm{~h}$ blood was collected by heart puncture after sacrifice. For the (cardio)vascular risk factor andatherosclerosis study, mice were randomized in 6 groups ( $n=15$ per group, $n=$ 20 in control group) and received, based on the results of the PK study, a once-daily oral gavage with nilotinib (10 or $30 \mathrm{mg} / \mathrm{kg}$ ), ponatinib ( 3 or $10 \mathrm{mg} / \mathrm{kg}$ ), or a twice-daily gavage with imatinib $(150 \mathrm{mg} / \mathrm{kg})$. The TKIs were suspended in 5\% carboxymethyl cellulose and all mice except the imatinib group received a second oral gavage with the vehicle alone (5\% carboxymethyl cellulose). The TKIs were purchased at LC laboratories, Woburn (MA), USA. After 12 weeks 5 mice of the control group were sacrificed to asses atherosclerosis development and to determine the end-point of the study. After sixteen weeks of treatment all animals were sacrificed by $\mathrm{CO}_{2}$ inhalation. Plasma cholesterol, triglycerides, HDL-C, lipoprotein profiles, SAA, E-selectin and MCP-1, aspartate transaminase (AST) and alanine transaminase (ALT) were measured throughout the study. Blood pressure was measured at 2 and 15 weeks of treatment. Measurement of hepatic lipid and protein content; protein and albumin content in broncho-alveolar lavage (BAL) fluid; urinary albumin/creatinine levels; and histology of lung and hearts was performed at 16 weeks. Total FVII coagulant activity was measured at 4 and 12 weeks and FVIIa activity at 4 weeks. Gene expression analysis using Next Generation Sequencing with the Illumina Nextseq 500 and subsequent pathway analysis of liver of 8 mice per group was performed following established protocols $(23,24)$. 
TABLE 1 | Pharmacokinetics of imatinib, nilotinib and ponatinib in APOE`3Leiden.CETP mice and CML-patients.

\begin{tabular}{|c|c|c|c|c|c|c|c|c|c|c|}
\hline \multirow[t]{2}{*}{ TKI } & \multicolumn{5}{|c|}{ APOE`3Leiden.CETP mice } & \multicolumn{5}{|c|}{ CML patients } \\
\hline & Dose & /kg) & $\mathrm{T}_{\max }(\mathrm{h})$ & $\underset{(\mu \mathrm{g} / \mathrm{mL})}{C_{\max }}$ & $\begin{array}{c}\text { AUC }_{0-24} \\
\left(\mu \mathrm{g} / \mathrm{mL}^{\star} \mathrm{h}\right)\end{array}$ & Dose (mg & kg) & Subject & $\begin{array}{c}\text { AUC }_{0-24} \\
\left(\mu \mathrm{g} / \mathrm{mL}^{*} h\right)\end{array}$ & Reference \\
\hline \multirow[t]{2}{*}{ Imatinib } & Single & 100 & 2.28 & 5.29 & 32.79 & Day 1, BID & 400 & CML-patients & $36.2 \pm 7.4$ & (25) \\
\hline & $\begin{array}{l}\text { Repeated } \\
\text { dose, BID }\end{array}$ & 150 & 2.47 & 11.07 & 78.13 & Steady state, BID & 400 & CML-patients & $68.4 \pm 29.8$ & (25) \\
\hline \multirow[t]{3}{*}{ Nilotinib } & Single & 50 & 3.26 & 10.97 & 117.49 & Single, QD & 400 & $\begin{array}{l}\text { Healthy } \\
\text { subjects }\end{array}$ & $14.7 \pm 5.0$ & (26) \\
\hline & Repeated & 10 & 3.17 & 2.30 & 24.60 & & & & & \\
\hline & $\begin{array}{l}\text { dose, QD } \\
\text { Repeated } \\
\text { dose, QD }\end{array}$ & 30 & 3.17 & 6.89 & 73.81 & Repeated dose, QD & $400-1,200$ & CML-patients & $36.0 \pm 11.8$ & (26) \\
\hline \multirow[t]{3}{*}{ Ponatinib } & Single & 5 & 8.00 & 0.19 & 3.24 & Single, QD & 60 & CML-patients & $0.7 \pm 0.4$ & (27) \\
\hline & $\begin{array}{l}\text { Repeated } \\
\text { dose QD }\end{array}$ & 3 & 6.72 & 0.14 & 2.43 & & & & & \\
\hline & $\begin{array}{l}\text { Repeated } \\
\text { dose, QD }\end{array}$ & 10 & 6.73 & 0.46 & 8.11 & Repeated dose, QD & $15-60$ & CML-patients & 1.3 & (28) \\
\hline
\end{tabular}

$T_{\text {max }} C_{\text {max }}$ and $A \cup C_{0-24}$ were calculated after a single dose or after 16 weeks of treatment (repeated dose) for imatinib, nilotinib and ponatinib and compared with plasma concentrations in CML patients. AUC, area under the curve; BID, twice a day; CML, chronic myoloid leukemia; QD, once a day. Data are presented as means (APOE ${ }^{3} L$ eiden. CETP mice) and means $\pm S D$ (CML-patients), unless $S D$ was not given in the reports.

\section{Statistical Analysis}

Significance of differences between the groups was calculated in SPSS 22.0 for Windows. Normally distributed data was tested parametrically using a one-way ANOVA for multiple comparisons with a Dunnett's post-hoc test. Non-parametric data were compared separately with a Mann-Whitney $U$ test with adjusted rejection criteria using a Bonferroni-Holm correction. Correlations between lesion size (after square root transformation) and cholesterol exposure were calculated with a Pearson's correlation test. All groups were compared with the control group. Values are presented as means $\pm \mathrm{SD}$ and $p$-values $<0.05$ were considered statistically significant.

For a more detailed description of the applied methods, please see the Supplementary material online (Data Sheet S1).

\section{RESULTS}

\section{PK Analysis and Plasma Drug Concentrations}

Pharmacokinetic analysis was performed after a single dose of imatinib (100 mg/kg), nilotinib (50 mg/kg) or ponatinib $(5 \mathrm{mg} / \mathrm{kg})$ (Table 1) and based on these results the doses for the atherosclerosis study were adjusted to twice daily $150 \mathrm{mg} / \mathrm{kg}$ for imatinib, once daily 10 or $30 \mathrm{mg} / \mathrm{kg}$ for nilotinib and once daily $3 \mathrm{or} 10 \mathrm{mg} / \mathrm{kg}$ for ponatinib. The relatively high dose of imatinib needed to achieve plasma concentrations comparable to those in CML-patients was due to the short half-life of the drug in mice and is in line with previous reports (29). Drug exposure after repeated dosing was measured in sacrifice plasma and calculated AUCs were similar to those in CML-patients for imatinib and the low doses of nilotinib and ponatinib (Table 1).

\section{Safety Aspects of Treatments with TKIs}

No clinical signs of deviant behavior and no effects on body weight and food intake were noted in any treatment group as compared with control. Plasma ALT and AST, measured at the start and after 16 weeks of treatment, showed no aberrant results (Table S1; Data Sheet S1). The number of circulating peripheral blood mononuclear cells (PBMC's) in the blood as measured by fluorescence-activated cell sorting (FACS) analysis at 12 weeks (Table S2; Data Sheet S1) was reduced by imatinib $(-42 \%, p=0.006)$ and by the high-dose ponatinib $(-44 \%, p=0.003)$. In addition, imatinib and the high doses of nilotinib and ponatinib decreased pro-inflammatory Ly6C high monocytes, all consistent with the mode of action of TKIs. Two mice (ponatinib $3 \mathrm{mg} / \mathrm{kg}$ ) died during blood pressure measurements at $\mathrm{t}=15$ weeks, and one mouse (nilotinib $30 \mathrm{mg} / \mathrm{kg}$ ) was excluded from atherosclerosis measurement due to deviating heart anatomy.

\section{(Cardio) Vascular Risk Factors Imatinib and Ponatinib Reduce Plasma Cholesterol Levels}

As dyslipidemia is a major risk factor for cardiovascular disease, we measured plasma cholesterol and triglyceride levels throughout the study, and HDL-C at the end point. The Western-type diet resulted in an average plasma cholesterol of $17.3 \pm 3.5 \mathrm{mmol} / \mathrm{L}$, triglycerides of $3.3 \pm 1.0 \mathrm{mmol} / \mathrm{L}$, and an HDL-C level of $1.4 \pm 0.2 \mathrm{mmol} / \mathrm{L}$ in the control group. When compared to the control group, imatinib reduced average cholesterol and triglyceride levels by $69 \%(p<$ $0.001)$ and $36 \%(p=0.019)$, respectively. Ponatinib decreased cholesterol levels by $37 \%(3 \mathrm{mg} / \mathrm{kg}, p<0.001)$ and $44 \%(10 \mathrm{mg} /$ $\mathrm{kg}, p<0.001$ ), whereas nilotinib had no significant effect on plasma lipid levels (Figure 1A-D). At 16 weeks of treatment, HDL-C was decreased by ponatinib in both the low $(-30 \%, p=0.003)$ and high $(-25 \%, p=0.016)$ dose. The reduction of plasma cholesterol by imatinib and ponatinib was mainly confined to VLDL-LDL (i.e., non-HDL) (Figure 1C). 


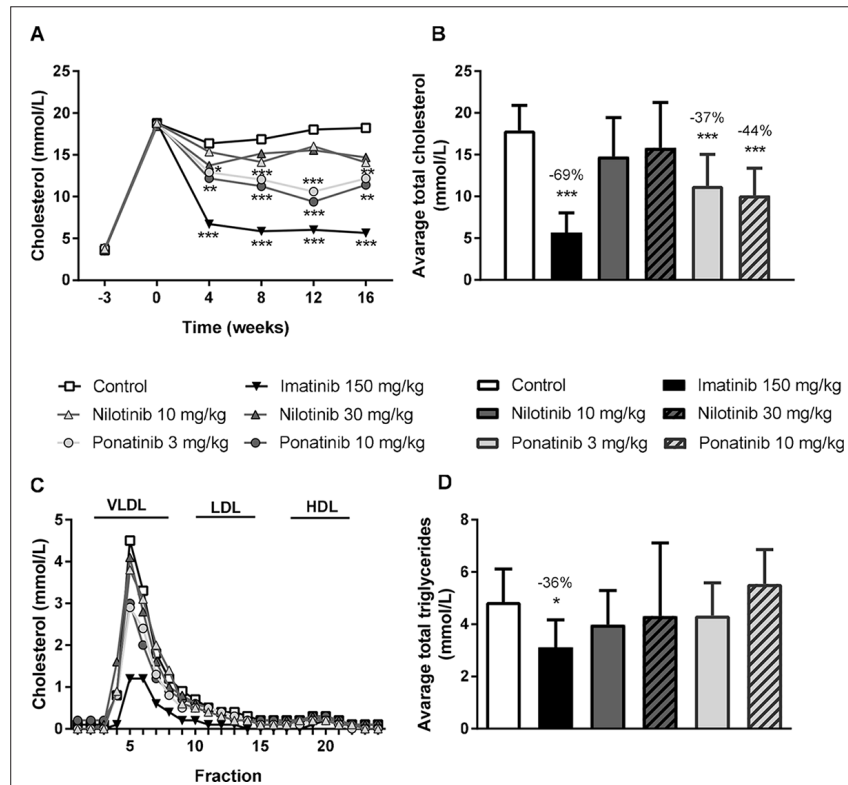

FIGURE 1 | Imatinib and ponatinib reduce plasma cholesterol levels and imatinib decreases average triglycerides. Plasma cholesterol was measured throughout the 16 week study $\mathbf{( A )}$ and average plasma cholesterol $\mathbf{( B )}$ and triglycerides (D) were calculated. Lipoprotein profiles were assessed by FPLC lipoprotein separation after 16 weeks of treatment (C). FPLC, Fast protein liquid chromatography; VLDL, very-low-density-lipoprotein; LDL, low-densitylipoprotein; HDL, high-density-lipoprotein. ${ }^{*} p<0.05,{ }^{* *} p<0.01{ }^{* \star} p<0.001$. Data are presented as means \pm SD ( $n=13-15$ per group).

These findings show that imatinib decreases plasma cholesterol and triglyceride levels in $\mathrm{APOE}^{\star} 3$ Leiden.CETP mice, which is consistent with the cholesterol-lowering effect observed in patients (30-33).

\section{Ponatinib and Imatinib Decrease Hepatic Lipid Content} Liver lipid storage may give insight into how lipid metabolism is affected by imatinib and ponatinib. Therefore, hepatic lipid content was measured by HPTLC. Free cholesterol content was decreased by $10 \mathrm{mg} / \mathrm{kg}$ ponatinib $(-21 \%, p=0.007)$ (Figure 2A), cholesterol ester content was decreased by imatinib $(-30 \%, p=0.001)$ and by both the low $(-49 \%, p<0.001)$ and high $(-61 \%, p<0.001)$ dose of ponatinib (Figure 2B). Triglyceride content was decreased by the low $(-32 \%, p$ $=0.048)$ and high $(-43 \%, p=0.005)$ dose of ponatinib (Figure 2C). These data point to a shortage of cholesterol in the liver and suggest that not cholesterol clearance, but VLDL production and/or intestinal absorption of cholesterol are affected by ponatinib and imatinib.

\section{Blood Pressure and Vascular Dysfunction}

Increased blood pressure and endothelial activation may lead to vascular dysfunction and atherosclerosis. Systolic blood pressure (SBP), measured after 2 and 15 weeks of treatment, was $91 \pm$ 7 and $86 \pm 5 \mathrm{mmHg}$, respectively, in the control group, and heart rate was $726 \pm 46$ and $716 \pm 29$ beats per minute. SBP and heart rate were not affected by imatinib, nilotinib or ponatinib treatment. As markers of vascular integrity and leakage or edema formation, we evaluated lung histology, determined the wet/dry weight ratio of the lungs and measured the amount of protein in the BAL fluid. None of the anti-CML drugs showed significant effects on histology and wet/dry weight ratio (data not shown), and ponatinib decreased the amount of protein in BAL fluid by $51 \%(3 \mathrm{mg} / \mathrm{kg}, p=0.029)$ and by $47 \%(10 \mathrm{mg} / \mathrm{kg}, p=0.041)$ (Figure S1A; Data Sheet S1). In contrast, ponatinib increased the urinary albumin/creatinine ratio (approximately 13-fold, N.S.), mainly due to 3 mice with very high levels of urinary albumin (Figure S1B; Data Sheet S1).

These data indicate that the anti-CML drugs did not cause damage to the microvasculature in the lungs but that ponatinib may lead to microvascular dysfunction in the kidney.

\section{Ponatinib Increases Plasma E-Selectin}

Inflammation is widely considered as an important contributing factor to cardiovascular events (34). Therefore, we measured plasma levels of macrophage-derived chemokine monocyte chemoattractant protein-1 (MCP-1), the adhesion molecule E-selectin as marker of endothelial activation, and serum amyloid A (SAA), an acute phase protein mainly produced by the liver (Table 2 ). None of the inflammatory markers were significantly altered by imatinib. The Western-type diet increased MCP-1 relative to baseline ( $\mathrm{T}=0$ weeks) $(+126 \%, p=0.015)$, as did nilotinib $(10 \mathrm{mg} / \mathrm{kg},+220 \%, p<0.001$; $30 \mathrm{mg} / \mathrm{kg},+160 \%, p<0.001)$. Ponatinib increased SAA relative to baseline $(+123 \%, p=0.013)$, but not relative to control. In four of the fifteen ponatinib-treated mice, E-selectin levels were 3 to 10 times increased, leading to an overall increase of $161 \%(p<0.001)$ when compared to control, which may point to endothelial activation by ponatinib. Collectively, these data confirm the safety profile of imatinib and suggest endothelial activation and potential endothelial dysfunction in some animals by ponatinib .

\section{Atherosclerosis Imatinib and Ponatinib Reduce Lesion Size and Severity}

Next we analyzed the effects of long-term exposure of the antiCML TKIs on the progression of atherosclerosis as a cardiovascular endpoint, as shown by representative images (Figure 3). Sixteen weeks of Western diet resulted in the development of $4.0 \pm 0.8$ atherosclerotic lesions and $156 \pm 61^{\star} 1,000 \mu \mathrm{m}^{2}$ lesion area per cross-section in the control group (Figure 4A). Approximately $55 \%$ of these lesions were severe (type IV-V) lesions and only $10 \%$ of the segments were unaffected (Figure 4B). The total number of lesions was not affected by any treatment (data not shown), but imatinib and ponatinib diminished the lesion area by $78(p<0.001), 52$ (3 $\mathrm{mg} / \mathrm{kg}, p=0.002)$, and $48 \%$ (10 $\mathrm{mg} / \mathrm{kg}, p=0.006)$, respectively (Figure 4A). In addition, the total lesion area that consisted of severe lesions was reduced by imatinib $(-56 \%, p<0.001)$ (Figure 4B). Next, we evaluated whether this anti-atherogenic effect of imatinib and ponatinib could be explained by the reduction in plasma cholesterol levels. The square root of the lesion size was positively correlated with plasma cholesterol exposure ( $\mathrm{mmol} / \mathrm{L}^{*}$ weeks) in control, imatinib and high dose nilotinib and ponatinib treated mice (control $\mathrm{R}^{2}=0.79, p=0.001$; imatinib $\mathrm{R}^{2}=0.71, p=0.003$; ponatinib $10 \mathrm{mg} / \mathrm{kg} \mathrm{R} \mathrm{R}^{2}=0.79, p<0.001$; nilotinib $30 \mathrm{mg} / \mathrm{kg} \mathrm{R}^{2}=$ $0.63, p=0.016$ ) (Figure 5). Lesion size per cross-section was not 
A

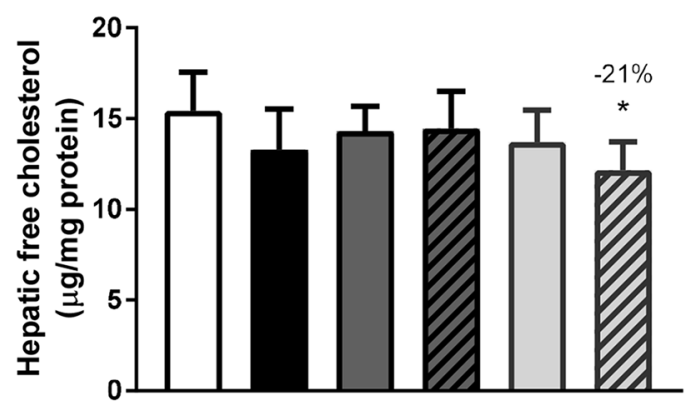

C

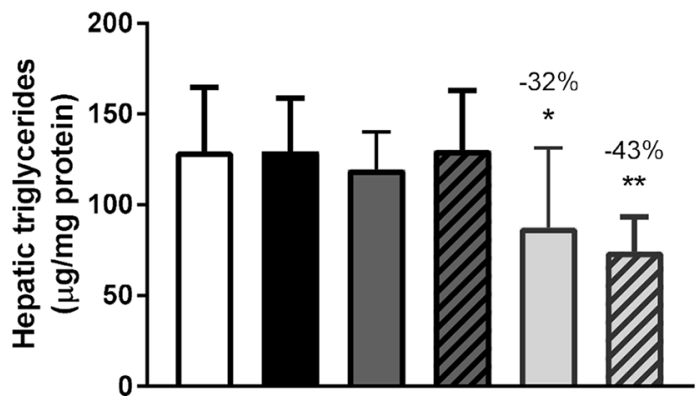

B

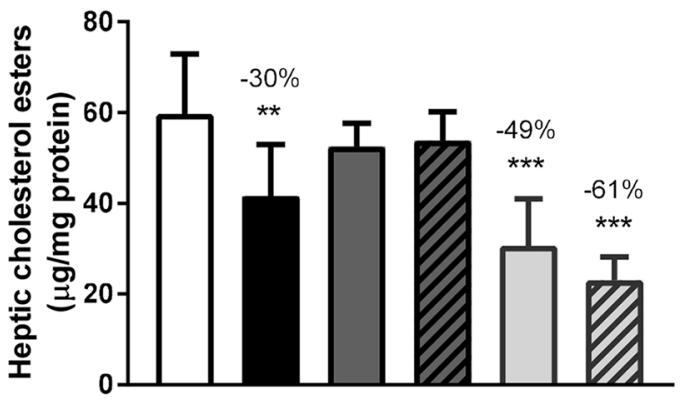

FIGURE 2 | Imatinib and ponatinib decrease hepatic lipid content. Hepatic free cholesterol (A), cholesterol ester (B) and triglyceride (C) content were measured by HPTLC after 16 weeks of treatment. HPTLC, high-performance thin-layer chromatography. ${ }^{*} p<0.05,{ }^{\star *} p<0.01{ }^{\star \star *} p<0.001$. Data are presented as means \pm SD $(n$ $=8$ per group).

correlated with inflammation markers or blood pressure, indicating a dominant role of plasma cholesterol and cholesterol-lowering by the drugs in the development of atherosclerosis.

\section{Imatinib Improves Plaque Morphology}

To assess the plaque phenotype as a marker for vulnerability to rupture, lesion morphology was analyzed in the type IV and V

TABLE 2 | Ponatinib increases markers of inflammation.

\begin{tabular}{lcccc}
\hline Treatment & $\begin{array}{c}\text { Dose } \\
(\boldsymbol{m g} / \mathbf{k g})\end{array}$ & $\begin{array}{c}\text { MCP-1 } \\
(\boldsymbol{p g} / \boldsymbol{m} \boldsymbol{L})\end{array}$ & $\begin{array}{c}\text { SAA } \\
(\boldsymbol{\mu} \boldsymbol{g} / \boldsymbol{m} \boldsymbol{L})\end{array}$ & $\begin{array}{c}\text { E-selectin } \\
(\boldsymbol{n g} / \boldsymbol{m} \boldsymbol{L})\end{array}$ \\
\hline Baseline & - & $45 \pm 23$ & $6.8 \pm 4.4$ & $87 \pm 9$ \\
Control & - & $102 \pm 44^{\dagger}$ & $10.1 \pm 1.2$ & $96 \pm 18$ \\
Imatinib & 150 & $54 \pm 44$ & $9.6 \pm 0.5$ & $71 \pm 18$ \\
Nilotinib & 10 & $144 \pm 82^{\ddagger}$ & $10.6 \pm 1.0$ & $79 \pm 23$ \\
& 30 & $117 \pm 60^{\ddagger}$ & $10.6 \pm 1.1$ & $99 \pm 17$ \\
Ponatinib & 3 & $78 \pm 29$ & $10.4 \pm 1.9$ & $77 \pm 22$ \\
& 10 & $92 \pm 68$ & $15.2 \pm 21.1^{\dagger}$ & $250 \pm 307^{\ddagger / *}$ \\
\hline
\end{tabular}

Effect of imatinib, nilotinib and ponatinib on inflammatory markers as measured at baseline ( $T=0$ weeks) and after 16 weeks of treatment. MCP-1, monocyte chemoattractant protein-1; SAA, serum amyloid $A$.

${ }^{*} p<0.001$, as compared to control.

${ }^{t} p<0.05$. as compared to baseline.

${ }^{\ddagger} p<0.001$ as compared to baseline. Data are presented as means $\pm S D(n=8-15$ per group). lesions from mice treated with imatinib and the high dosages of nilotinib and ponatinib, as shown by representative images (Figure 3). The macrophage and necrosis content were quantified as factors that decrease plaque stability, and smooth muscle cell area in the cap of the lesions and collagen as factors that improve plaque stability $(17,35,36)$ (Figure 6A). Average macrophage, necrotic core, collagen and smooth muscle cell content in the control group were $24 \pm 8 \%, 4 \pm 2 \%, 42 \pm 10 \%$ and $4 \pm 3 \%$, respectively (Figure 6A). Imatinib increased the collagen content by $47 \%(62 \pm 17 \%, p=0.004)$ and tended to increase aSMC content $(+38 \%, p=0.050)$, resulting in an enhanced lesion stability index $(+216 \%, p=0.004)$ (Figure 6B). Nilotinib $(10 \mathrm{mg} / \mathrm{kg})$ decreased collagen content $(-32 \%, p=0.003)$, resulting in a decreased lesion stability index $(-43 \%, p=0.003)$. Ponatinib $(3 \mathrm{mg} / \mathrm{kg})$ decreased necrotic core content $(-58 \%, p=0.001)$ without affecting plaque stability. Collectively, these data indicate that imatinib induces a more stable plaque phenotype with collagen-rich lesions.

\section{Transcriptome Analysis Ponatinib Adversely Alters Gene Expression of Coagulation Factors}

To find early molecular signatures of other clinically relevant processes induced by the anti-CML drugs, gene expression and 


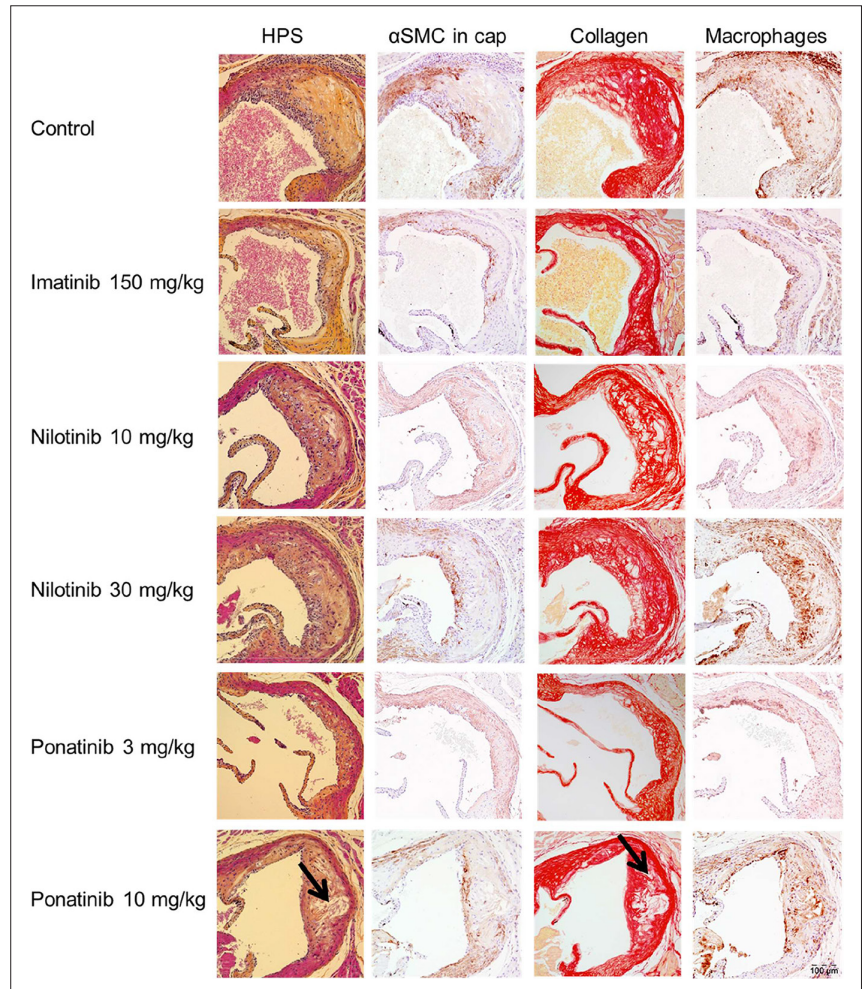

FIGURE 3 | Effect of imatinib, nilotinib and ponatinib on plaque composition. Representative images of HPS staining, immunostaining with $\alpha$-actin for SMCs, Sirius red staining for collagen and immunostaining with Mac-3 for macrophages. The arrows depict necrotic areas, including cholesterol clefts. Images were taken with an Olympus BX 51 microscope using Olympus analySIS image processing software cell^D. Original magnification $\times 16$. HPS, hematoxylin-phloxine-saffron; SMCs, smooth muscle cells; MAC-3, Purified anti-mouse CD107b Mac-3 Antibody.

pathway analysis was performed in the liver as the central organ in lipid metabolism and synthesis of coagulation factors. To identify drug-specific molecular responses and overlap between the various treatments, the total number of differentially expressed genes (DEG) was assessed and a Venn-diagram was constructed comprising all DEG compared to control group. Both ponatinib and nilotinib displayed a dose-dependent increase in the total number of DEG as compared to control and the molecular response of the highdose ponatinib had more overlapping genes with imatinib than nilotinib (Figure S2; Data Sheet S1).

General categorization of biological functions showed that all anti-CML drugs affect canonical pathways associated with mitochondrial dysfunction and oxidative phosphorylation, most likely induced by oxidative stress and leading to reduced energy production, and processes involved in protein synthesis and cell growth (EIF2 signaling), confirming the target-related molecular responses of anti-CML drugs. ( Figure S3; Data Sheet S1).

The processes relevant to (cardio)vascular (side) effects of the anti-CML drugs are highlighted in Figure S4; Data Sheet S1 and Figure 7. Although gene expression data from the liver cannot be directly extrapolated to atherosclerosis signaling in the vascular wall, gene expression profiles of different organs have affiliation with each other and may be predictive for these biological processes. Therefore, the transcriptome data of the liver as predicting organ are given. As compared to the other TKI's, imatinib showed the most pronounced effects on atherosclerosis signaling, with favorable regulation of genes involved in cell adhesion (Integrin $\beta 2$ and $\alpha 4$, Icam1, Vcam1, Psgl-1), macrophage activation (Cd40, Tnfrsf14, Scara1, Nfkb), lipid regulation (Lpl, Apoa1, Apoa2, Apoc2, Apoc4, Pla2g7), inflammatory processes (Cd40, Nfkb, Il1a, Tnfrsf14, Icam1, Vcam1) and genes related to extracellular matrix modulation (Col1a2, Col3a1, Col1a1, Mmp13, $\mathrm{Tgf}-\beta$ ) (Figure S4 A-B data; Data Sheet S1). Ponatinib showed similar effects, but to a lesser extent, whereas these effects were not observed after nilotinib treatment (Figure S4 A; Data Sheet S1).

As the site of synthesis of a large number of coagulation factors, the liver plays an important role in the regulation of hemostatic and thrombotic processes. Although all three TKIs to some extent affected the coagulation pathways, ponatinib had the most adverse profile (Figure 7). Ponatinib increased the gene expression of members of the intrinsic or contact activation pathway, Kngla and Klkb1, mainly involved in growth of a thrombus, and of the extrinsic or tissue factor pathway F7, involved in initiation of thrombus formation, and decreased gene expression of Upa and Tpa, both involved in fibrinolysis. Nilotinib showed down-regulation of the expression of F5, F9, and Protein S, while Serpina1 (PAI-1) was up-regulated. Imatinib down-regulated the expression of Upa, Tpa and Protein $S$ and up-regulated Serpina1 and Protein $C$. This analysis demonstrates that among the three anti-CML drugs investigated ponatinib most prominently induces adverse alterations in the gene expression of coagulation factors in both the intrinsic and extrinsic pathway, which may lead to a state of hypercoagulability.

\section{Coagulation}

\section{Ponatinib Increases Plasma Factor VII and Nilotinib Increases Factor VIla Activity}

Next, we measured total factor VII coagulant activity (FVII) and VIIa activity (FVIIa) in plasma. Ponatinib increased FVII after 4 weeks $(10 \mathrm{mg} / \mathrm{kg},+265 \%, p<0.001)$ and 12 weeks of treatment $(3 \mathrm{mg} / \mathrm{kg}$, $+28 \%, p=0.07 ; 10 \mathrm{mg} / \mathrm{kg}+82 \%, p<0.001$ ) (Figure 8A). In addition, nilotinib increased the activity of FVIIa at 4 weeks by $82 \%(30 \mathrm{mg} / \mathrm{kg}$, $p<0.001$ ) (Figure 8B). Together, these data confirm our findings on gene expression analysis and reveal the pro-thrombotic characteristics of nilotinib and ponatinib.

\section{DISCUSSION}

This is the first study that compared the effect of a first, second and third generation BCR-ABL1 tyrosine kinase inhibitor on (cardio) vascular risk factors and atherosclerosis. Imatinib and ponatinib decreased plasma cholesterol and atherosclerosis, while nilotinib and ponatinib activated coagulation. The pharmacokinetic data we provide enabled us to use drug exposures translatable to CMLpatients and can be used to optimize future TKI research. In addition, we provide a robust data set obtained by gene expression and pathway analysis of the liver, which predicted that ponatinib may lead to a procoagulant state by adversely affecting coagulation factors of both the contact activation (intrinsic) and tissue factor (extrinsic) pathways, which was confirmed by increased levels of the coagulation factor VII. 

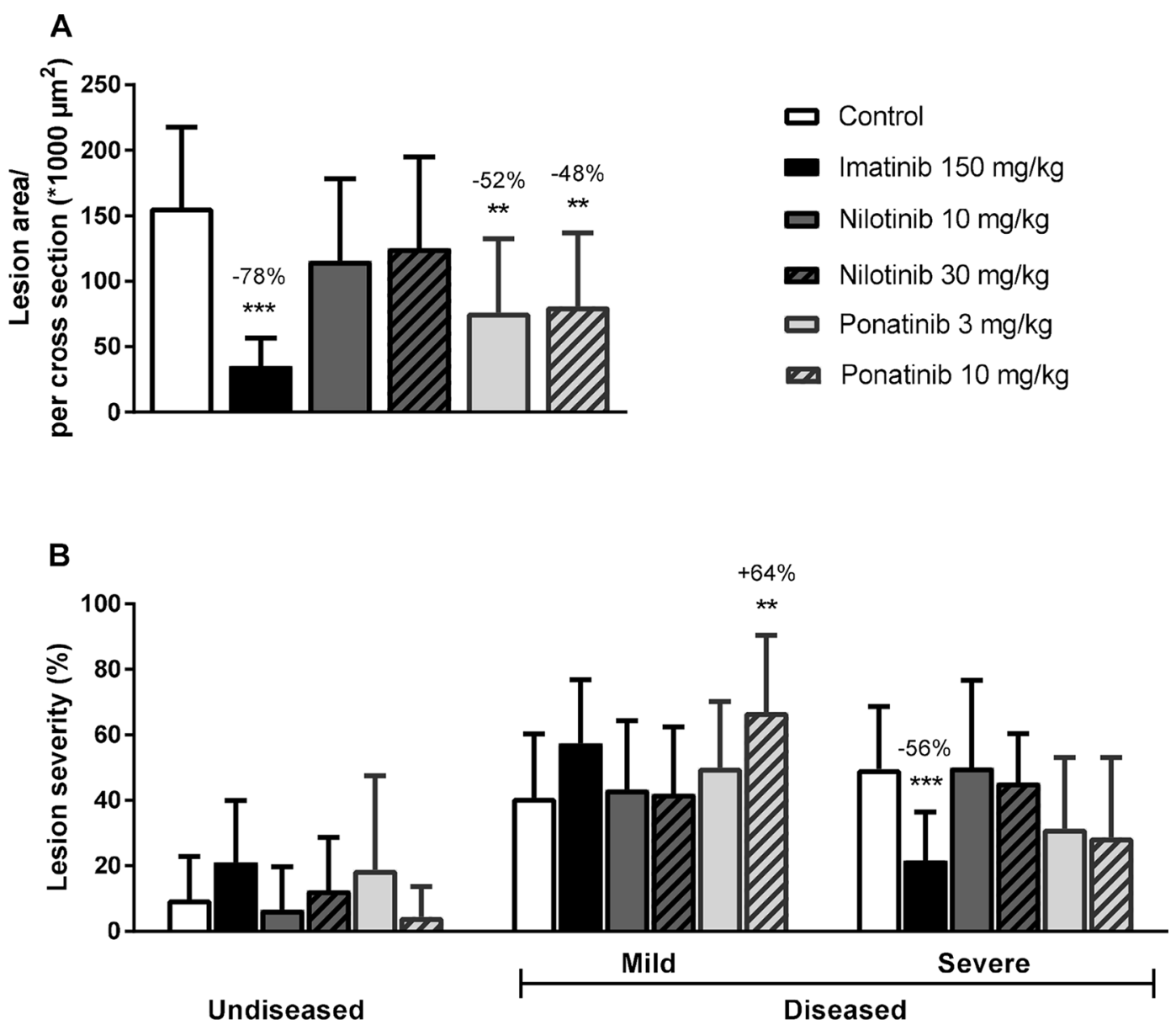

FIGURE 4 | Imatinib and ponatinib reduce atherosclerotic progression. After 16 weeks of treatment, the total lesion area per cross-section was assessed (A). Lesion severity was assessed, categorized as no lesions/undiseased, mild lesions (type I-III) and severe lesions (type IV-V) and expressed as percentage of total lesion area. (B). ${ }^{\star *} p<0.01{ }^{* \star *} p<0.001$. Data are presented as means $\pm \operatorname{SD}(n=13-15$ per group).

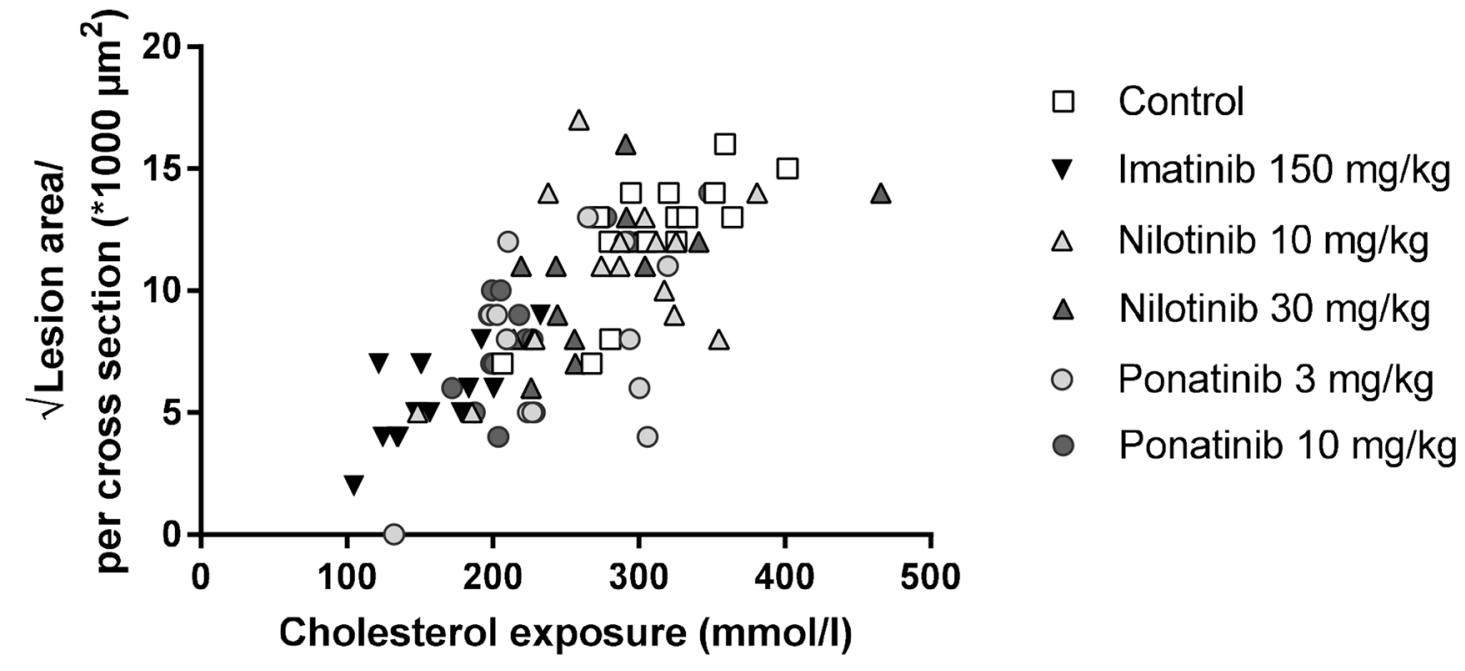

FIGURE 5 | Atherosclerotic lesion area is correlated with cholesterol exposure. Correlation between cholesterol exposure (mmol/L*weeks) and the square root of the lesion area was calculated with a Pearsons's correlation test ( $n=13-15$ per group). 

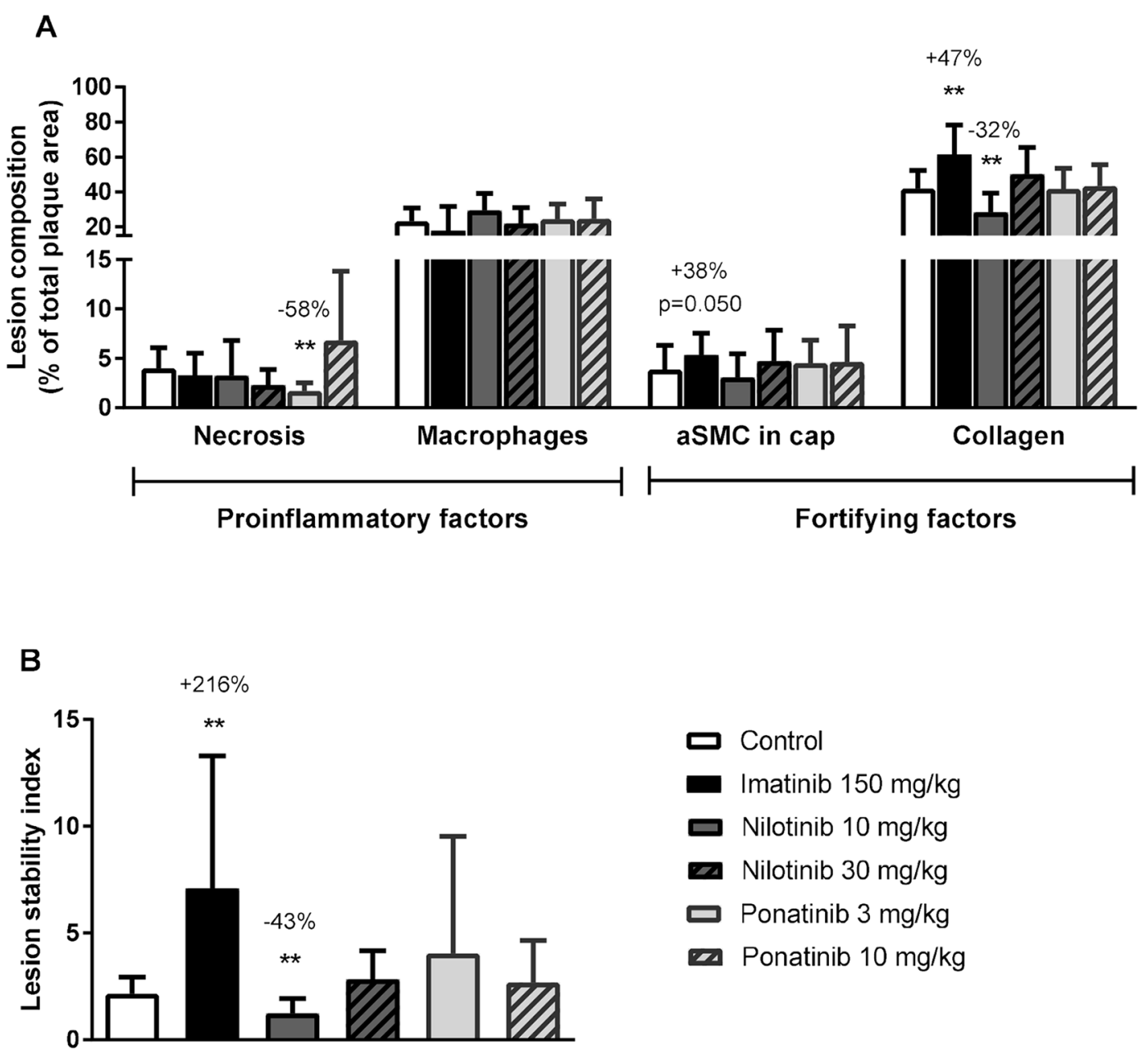

FIGURE 6 | Imatinib increases plaque stability. Necrotic and macrophage content as pro-inflammatory factors, and $\alpha$ SMCs and collagen as fortifying factors, were determined in the severe (type IV-V) lesions and expressed as percentage of total plaque area (A). Plaque stability index was calculated (B). aSMC; $\alpha$ smooth muscle cell., ${ }^{\star \star} p<0.01$. Data are presented as means $\pm \operatorname{SD}(n=13-15$ per group).

In addition, nilotinib increased activity of FVIIa. These findings can be used by clinicians to carefully monitor coagulation parameters in CML-patients to predict risk of cardiovascular events.

The choice to perform this study in a non-leukemic mouse model has several reasons. First, there is, inherent to the diagnosis and progression of the disease, a shortage of suitable high quality plasma samples of CML patients collected at both baseline and follow-up under similar conditions. Second, CML affects both metabolic (10) and coagulation (11) parameters which makes it difficult to elucidate the role of TKI treatment on the reported VAEs independently of the underlying disease. Last, we were able to investigate a broad range of parameters, including atherosclerosis and gene expression and pathway analysis of the liver, which is not possible in CML-patients.

Imatinib and ponatinib, but not nilotinib, decreased plasma cholesterol contained in the pro-atherogenic apoB-containing lipoproteins. Cholesterol reduction and even normalization in hypercholesterolemic CML-patients is repeatedly described in retrospective studies with CML-patients for imatinib (30-32, 37) and is consistent with our findings. Data on ponatinib are scarce (37) and it is unclear whether nilotinib affects plasma cholesterol in
CML-patients. Some studies reported increased plasma cholesterol (5, $8,33,37$ ), whereas others question this (38). These opposing findings may be explained by the response to the underlying disease. It should be noted that nilotinib is often prescribed as a second-line treatment after resistance to imatinib. Reduced caloric intake induced by the leukemia and increased energy requirements imposed by tumor growth may result in lower cholesterol levels at baseline, while a positive response to treatment is often accompanied by increased cholesterol levels in oncologic patients (39). This response-related cholesterol elevation may be abolished by the cholesterol-lowering effects of imatinib and ponatinib per se as found in our study, resulting in decreased (imatinib) or normalized (ponatinib) plasma cholesterol levels in CML patients.

Several mechanisms are involved in cholesterol homeostasis, including intestinal uptake, hepatic uptake and secretion as lipoproteins, synthesis and storage, and fecal excretion. The decreased hepatic lipid content in imatinib and ponatinib treated mice (Figure 2) points to a shortage of cholesterol in the liver and suggests that not lipoprotein clearance, but VLDL production and/or intestinal absorption of cholesterol are affected by imatinib and ponatinib. 


\section{A Genes in coagulation system}

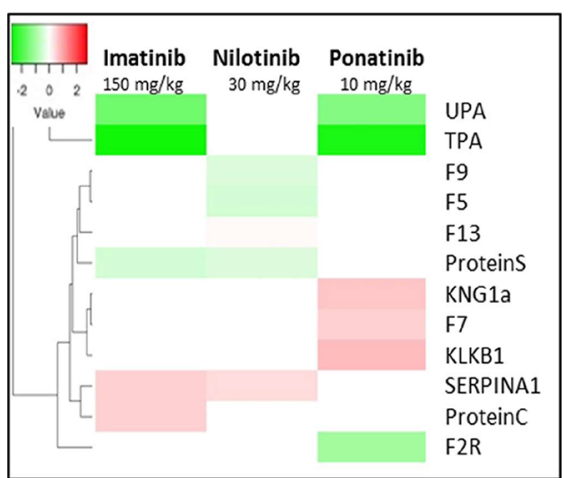

C Nilotinib $30 \mathrm{mg} / \mathrm{kg}$

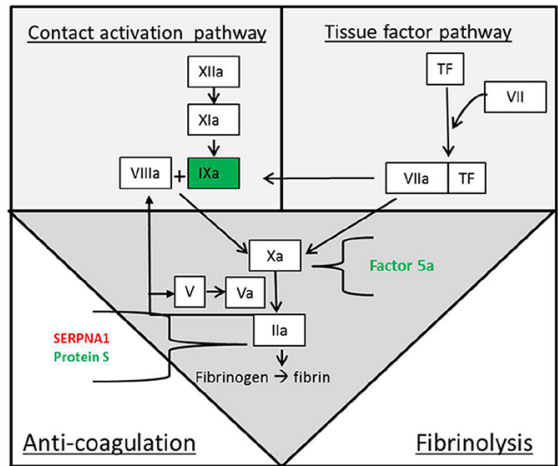

\section{B Imatinib $150 \mathrm{mg} / \mathrm{kg}$}

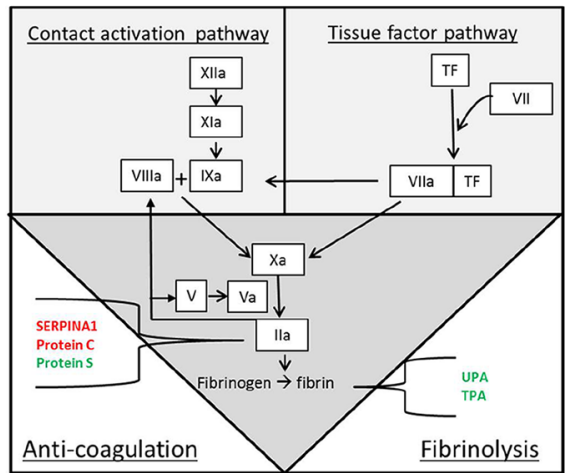

D Ponatinib $10 \mathrm{mg} / \mathrm{kg}$

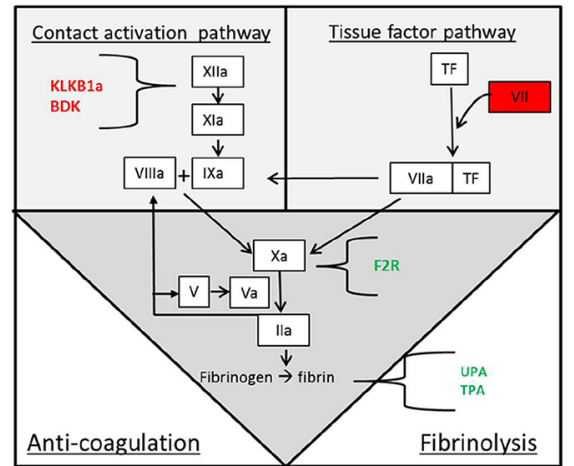

FIGURE 7 | Genes in the coagulation system regulated by imatinib, nilotinib and ponatinib. The heat map shows all significantly (<0.01) upregulated (red) and downregulated (green) genes involved in coagulation of mice treated with imatinib (150 mg/kg), nilotinib (30 mg/kg) or ponatinib (10 mg/kg) as compared to control mice (A). Imatinib regulates genes involved in anti-coagulation and fibrinolysis (B). Factor 9a and 5a were down-regulated and SERPINA1 up-regulated by nilotinib (C). Ponatinib showed the most adverse profile with upregulation of genes in both the contact activation and tissue factor pathway, together with downregulation of genes involved in fibrinolysis (D). $p$-values of $<0.01$ were used as cut-off ( $n=8$ per group).

Indeed, when myeloid tumor cells are treated with imatinib, de novo fatty acid synthesis is reduced, pointing towards decreased VLDL particle production (40). However, besides the shared activity of TKIs used for CML-treatment against the BCR-ABL1 tyrosine kinase, the potency and activity to affect off-target kinases differs markedly, and thus different processes may be involved. To our knowledge, no in vivo studies are available that investigated the effects of TKI treatment on cholesterol and lipoprotein metabolism, and functional studies are required.

Important observations from our study are the reduced development of atherosclerosis by imatinib and ponatinib which was correlated to decreased plasma cholesterol levels, and the increased plaque stability induced by imatinib, which has not been reported previously by others. There are no reports that describe the effect of ponatinib on atherosclerosis development in an animal model, and there are inconsistent reports on imatinib and nilotinib. In line with our findings, imatinib reduced atherosclerosis in STZ-induced diabetic $\mathrm{ApoE}^{-/-}$mice (41) and high fat fed $\mathrm{ApoE}^{-/-}$mice (42), though lesion reduction was independent of plasma cholesterol lowering and attributed to vascular wall remodeling and reduced inflammation. Interestingly, and in contrast with previous (41-43) and the present findings, Hadzijusufovic et al (43). did not find an effect of imatinib on atherosclerosis in $\mathrm{ApoE}^{-/-}$mice, but reported increased atherosclerosis by nilotinib. In addition, a direct proatherogenic effect on human endothelial cells was found, as shown by upregulation of adhesion factors ICAM-1, E-selectin and VCAM-1 (44), which is in line with the increase of markers of endothelial activation found in CML patients treated with nilotinib (45). Unfortunately, no data on plasma cholesterol and markers of endothelial activation in the mice were provided. We do not have a clear explanation for the discrepancy with our findings, but the use of different animal models and dosages, as well as the underlying disease may play a role.

Ponatinib increased plasma E-selectin and urinary albumin:creatinin in some animals, suggesting endothelial activation and potential endothelial dysfunction, wherein aberrant angiogenesis might be involved. Indeed, an in vitro study using HUVECs demonstrated the potential of ponatinib to reduce endothelium viability, and to induce apoptosis, reduce migration, inhibit tube formation, and to negatively affect endothelial progenitor cell function, all important for angiogenesis (46). In addition, ponatinib reduced vWF expression on lung endothelial cells in rats (47), which 

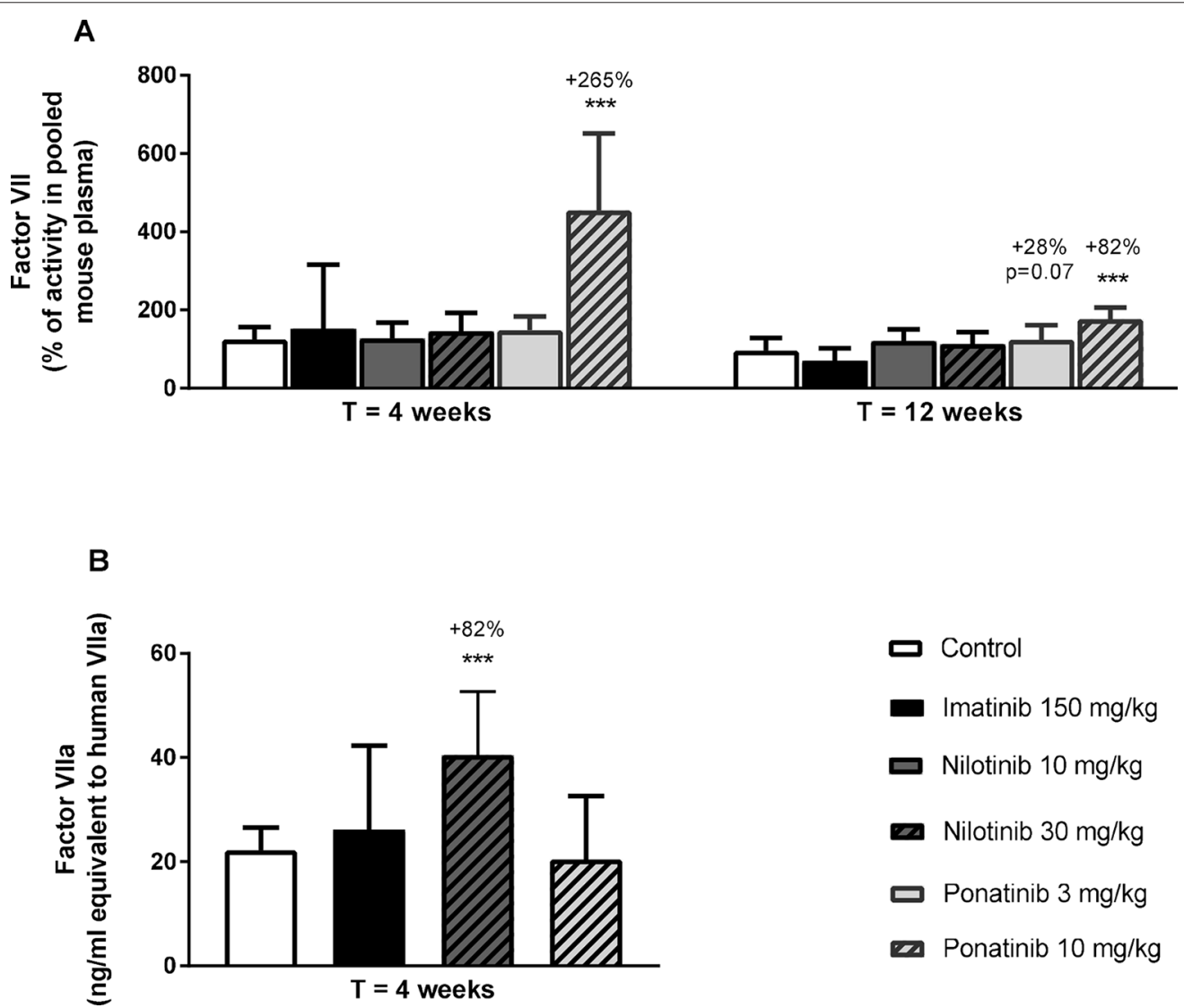

FIGURE 8 | Ponatinib increases factor VII and nilotinib increases factor VIla activity. Factor VII was measured after 4 and 12 weeks of treatment as the percentage of activity in reference pooled mouse plasma (A). Factor VIla activity was measured after 4 weeks of treatment $(\mathbf{B})$. ${ }^{\star \star *} p<0.001$. Data are presented as means $\pm \mathrm{SD}$ ( $n=6-20$ per group).

is an interesting finding, because vWF is not only a specific marker for ECs, but also functions in coagulation.

Although there were no clinical signs of thrombosis or bleeding in our long term study, an unbiased and exploratory transcriptome analysis revealed that ponatinib treatment lead to a pro-thrombotic state by affecting important players in the activation of the coagulation pathway. Ponatinib increased gene expression of Klkb1, Kng1a (part of the intrinsic or contact activation pathway) and F7 (part of the extrinsic or tissue factor pathway) and decreased expression of Upa and Tpa, which function in resolution of thrombi by fibrinolysis. Consistent with the increased gene expression, plasma levels of factor VII were increased by $265 \%$. Nilotinib had less pronounced effects on gene expression of coagulation factors but increased activity of FVIIa by $82 \%$. Using a different experimental design, Alhawiti et al (45). recently reported that a single dose of nilotinib but not imatinib increased platelet aggregation and thrombus growth ex vivo and in vivo in mice, and increased ex vivo platelet adhesion and thrombin generation in CML-patients receiving nilotinib (45). On the other hand, Loren et al (48). demonstrated that ponatinib, but not imatinib and nilotinib, inhibited ex vivo human platelet activation, spreading and aggregation, and hypothesized that the cardiovascular events observed in patients treated with ponatinib may be the result of effects on other organs and cell types. Indeed, we show that FVII is involved, which is produced by the liver, and is an important factor in the coagulation pathway. Mice lacking FVII have delayed thrombus formation (49) and pharmacological doses of rFVIIa induce hemostasis in severe hemophilia and in non-hemophilia patients with profuse, heavy bleeding (50). Collectively, these data indicate that nilotinib and ponatinib can both potentiate a pro-thrombotic state via different mechanisms of action.

The presence of one or more risk factors for (cardio)-metabolic disease together with the increased platelet aggregation and increased plasma activity of factor VII/VIIa may contribute to the onset of thrombosis, especially when combined with increased levels of tissue factor (TF), which activates the tissue factor pathway (Figure 7). Hypercoagulability has been described in a variety of malignancies, including hematological malignancies $(51,52)$, and many tumor cells express high levels of TF, the primary initiator of the extrinsic coagulation pathway (53). Therefore, we propose that nilotinib and ponatinib induce (athero) thrombosis in a subgroup of CML-patients through a combination of (cardio)-metabolic risk factors, enhanced levels of TF and increased plasma levels of coagulation factors. Our findings can be used to develop a multivariate risk model for CVD in CML patients, which include (cardio) vascular risk factors and coagulation parameters at baseline and during treatment, facilitating an early detection strategy for patients prone to cardiovascular events, which will improve therapy decision and patient care. 
In conclusion, using a comprehensive approach to measure the cardiovascular effects of various BCR-ABL inhibitors, we demonstrate that first, second and third generation BCR-ABL inhibitors have very distinct effects on lipid metabolism, blood coagulability and atherosclerosis. The first-generation inhibitor imatinib was proven safe, with evident benefit for plasma lipid concentrations, atherosclerotic plaque size and stability. The third-generation inhibitor ponatinib showed similar, albeit less pronounced effects on lipid concentrations and atherosclerosis, but also showed a hypercoagulable phenotype. These data perfectly match retrospective clinical observations on cardiovascular effects of BCR-ABL inhibitors, and besides providing a biological basis for these observations, may well contribute to safer application of these drugs in the future.

\section{DATA STATEMENT}

The RNAseq data is uploaded in GEO and available at https://www. ncbi.nlm.nih.gov/geo/query/acc.cgi?acc=GSE103908

\section{ETHICS STATEMENT}

Animal experiments were approved by the Institutional Animal Care and Use Committee of The Netherlands Organization for Applied Research under registration number 3557.

\section{AUTHOR CONTRIBUTIONS}

MP performed the research, analyzed the data and wrote the paper. EP designed the research, performed the research and analyzed the data. LV and MC performed and analyzed the gene expression analysis. CK developed the plasma coagulation factor assays and analyzed the plasma samples. RG designed the research and analyzed the PK data. JA analyzed the data and edited the paper. WJ edited the paper. HP designed the research, analyzed the data and edited the paper.

\section{REFERENCES}

1. de Klein A, van Kessel AG, Grosveld G, Bartram CR, Hagemeijer A, Bootsma $\mathrm{D}$, et al. A cellular oncogene is translocated to the Philadelphia chromosome in chronic myelocytic leukaemia. Nature (1982) 300(5894):765-7. doi: $10.1038 / 300765 \mathrm{a} 0$

2. Druker BJ, Guilhot F, O'Brien SG, Gathmann I, Kantarjian H, Gattermann $\mathrm{N}$, et al. Five-year follow-up of patients receiving imatinib for chronic myeloid leukemia. N Engl J Med (2006) 355(23):2408-17. doi: 10.1056/NEJMoa062867

3. O'Hare T, Walters DK, Stoffregen EP, Jia T, Manley PW, Mestan J, et al. In vitro activity of Bcr-Abl inhibitors AMN107 and BMS-354825 against clinically relevant imatinib-resistant Abl kinase domain mutants. Cancer Res (2005) 65(11):4500-5. doi: 10.1158/0008-5472.CAN-05-0259

4. Cortes JE, Kim DW, Pinilla-Ibarz J, le Coutre P, Paquette R, Chuah C, et al. A phase 2 trial of ponatinib in Philadelphia chromosome-positive leukemias. NEngl $J$ Med (2013) 369(19):1783-96. doi: 10.1056/NEJMoa1306494

5. Castagnetti F, Breccia M, Gugliotta G, Martino B, D'Adda M, Stagno F, et al. Nilotinib $300 \mathrm{mg}$ twice daily: an academic single-arm study of newly diagnosed chronic phase chronic myeloid leukemia

\section{DISCLAIMER}

CK has ownership interests in "Good Biomarker Sciences". WJ received research grants from and was speaker on (CMEaccredited) meetings sponsored by Amgen, Astellas, AstraZeneca, Daiichi Sankyo, Lilly, Merck-Schering-Plough, Pfizer, Roche, Sanofi-Aventis, the Netherlands Heart Foundation, the Interuniversity Cardiology Institute of the Netherlands, and the European Community Framework KP7 Program. RG is employee at Bristol-Meyers Squibb, New York, USA. MP, EP LV, MC, HP and JA have nothing to disclose.

\section{FUNDING}

This work was supported in part by Bristol-Meyers Squibb, New York, USA, by an allowance for TKI-LSH from the Ministry of Economic Affairs in the Netherlands (TKI1413P01), the TNO research program "Preventive Health Technologies" and the European Union Seventh Framework Programme (FP7/2007-2013) grant nr. 602936 (CarTarDis project). JA is funded by the Dutch Heart Foundation (Grant number 2014T064).

\section{ACKNOWLEDGMENTS}

The authors thank Anne Kozijn (TNO) for her help with the FACS analysis, Joost Westerhout (TNO) for the analysis of the pharmacokinetics and Kees van Leuven (GBS) for performing the measurements of coagulation factors.

\section{SUPPLEMENTARY MATERIAL}

The Supplementary Material for this article can be found online at: http://journal.frontiersin.org/article/10.3389/fcvm.2018.00055/ full\#supplementary-material

patients. Haematologica (2016) 101(10):1200-7. doi: 10.3324/ haematol.2016.144949

6. Moslehi JJ, Deininger M. Tyrosine kinase Inhibitor-Associated cardiovascular toxicity in chronic myeloid leukemia. J Clin Oncol (2015) 33(35):4210-8. doi: 10.1200/JCO.2015.62.4718

7. Valent P, Hadzijusufovic E, Schernthaner GH, Wolf D, Rea D, Le Coutre P. Vascular safety issues in CML patients treated with BCR/ABL1 kinase inhibitors. Blood (2015) 125(6):901-6. doi: 10.1182/blood-2014-09-594432

8. Kim TD, Rea D, Schwarz M, Grille P, Nicolini FE, Rosti G, et al. Peripheral artery occlusive disease in chronic phase chronic myeloid leukemia patients treated with nilotinib or imatinib. Leukemia (2013) 27(6):1316-21. doi: 10.1038/leu.2013.70

9. Tefferi A. Nilotinib treatment-associated accelerated atherosclerosis: when is the risk justified? Leukemia (2013) 27(9):1939-40. doi: 10.1038/leu.2013.112

10. Muller CP, Wagner AU, Maucher C, Steinke B. Hypocholesterolemia, an unfavorable feature of prognostic value in chronic myeloid leukemia. Eur J Haematol (1989) 43(3):235-9. doi: 10.1111/j.1600-0609.1989.tb00288.x

11. Wehmeier A, Daum I, Jamin H, Schneider W. Incidence and clinical risk factors for bleeding and thrombotic complications in myeloproliferative 
disorders. A retrospective analysis of 260 patients. Ann Hematol (1991) 63(2):101-6.

12. van der Hoogt CC, de Haan W, Westerterp M, Hoekstra M, Dallinga-Thie GM, Romijn JA, et al. Fenofibrate increases HDL-cholesterol by reducing cholesteryl ester transfer protein expression. J Lipid Res (2007) 48(8):1763-71. doi: 10.1194/jlr.M700108-JLR200

13. de Haan W, van der Hoogt CC, Westerterp M, Hoekstra M, Dallinga-Thie GM, Princen HM, et al. Atorvastatin increases HDL cholesterol by reducing CETP expression in cholesterol-fed $\mathrm{APOE}^{\star} 3$-Leiden.CETP mice. Atherosclerosis (2008) 197(1):57-63. doi: 10.1016/j.atherosclerosis.2007.08.001

14. van der Hoorn JW, de Haan W, Berbée JF, Havekes LM, Jukema JW, Rensen PC, et al. Niacin increases HDL by reducing hepatic expression and plasma levels of cholesteryl ester transfer protein in APOE 3 Leiden.CETP mice. Arterioscler Thromb Vasc Biol (2008) 28(11):2016-22. doi: 10.1161/ ATVBAHA.108.171363

15. Ason B, van der Hoorn JW, Chan J, Lee E, Pieterman EJ, Nguyen KK, et al. PCSK9 inhibition fails to alter hepatic LDLR, circulating cholesterol, and atherosclerosis in the absence of ApoE. J Lipid Res (2014) 55(11):2370-9. doi: 10.1194/jlr.M053207

16. Kühnast S, van der Hoorn JW, Pieterman EJ, van den Hoek AM, Sasiela WJ, Gusarova V. improves the plaque morphology, and enhances the effects of a statin. J Lipid Res (2014) 55(10):2103-12.

17. Kühnast S, van der Tuin SJ, van der Hoorn JW, van Klinken JB, Simic B, Pieterman E, et al. Anacetrapib reduces progression of atherosclerosis, mainly by reducing non-HDL-cholesterol, improves lesion stability and adds to the beneficial effects of atorvastatin. Eur Heart J (2015) 36(1):39-50. doi: 10.1093/ eurheartj/ehu319

18. Dewey FE, Gusarova V, Dunbar RL, O'Dushlaine C, Schurmann C, Gottesman O, et al. Genetic and pharmacologic inactivation of ANGPTL3 and cardiovascular disease. N Engl J Med (2017) 377(3):211-21. doi: 10.1056/ NEJMoa1612790

19. de Vries-van der Weij J, de Haan W, Hu L, Kuif M, Oei HL, van der Hoorn $\mathrm{JW}$, et al. Bexarotene induces dyslipidemia by increased very low-density lipoprotein production and cholesteryl ester transfer protein-mediated reduction of high-density lipoprotein. Endocrinology (2009) 150(5):2368-75. doi: 10.1210/en.2008-1540

20. van Vlijmen BJ, van 't Hof HB, Mol MJ, van der Boom H, van der Zee A, Frants RR, et al. Modulation of very low density lipoprotein production and clearance contributes to age- and gender- dependent hyperlipoproteinemia in apolipoprotein E3-Leiden transgenic mice. J Clin Invest (1996) 97(5):1184-92. doi: 10.1172/JCI118532

21. Groot PH, van Vlijmen BJ, Benson GM, Hofker MH, Schiffelers R, VidgeonHart M, et al. Quantitative assessment of aortic atherosclerosis in $\mathrm{APOE}^{\star} 3$ Leiden transgenic mice and its relationship to serum cholesterol exposure. Arterioscler Thromb Vasc Biol (1996) 16(8):926-33. doi: 10.1161/01. ATV.16.8.926

22. Trion A, de Maat MP, Jukema JW, van der Laarse A, Maas MC, Offerman EH, et al. No effect of C-reactive protein on early atherosclerosis development in apolipoprotein $\mathrm{E}^{\star} 3$-leiden/human C-reactive protein transgenic mice. Arterioscler Thromb Vasc Biol (2005) 25(8):1635-40. doi: 10.1161/01. ATV.0000171992.36710.1e

23. Kleemann R, Verschuren L, van Erk MJ, Nikolsky Y, Cnubben NH, Verheij $\mathrm{ER}$, et al. Atherosclerosis and liver inflammation induced by increased dietary cholesterol intake: a combined transcriptomics and metabolomics analysis. Genome Biol (2007) 8(9):R200. doi: 10.1186/gb-2007-8-9-r200

24. Verschuren L, Radonjic M, Wielinga PY, Kelder T, Kooistra T, van Ommen B, et al. Systems biology analysis unravels the complementary action of combined rosuvastatin and ezetimibe therapy. Pharmacogenet Genomics (2012) 22(12):837-45. doi: 10.1097/FPC.0b013e328359d274

25. Peng B, Hayes M, Resta D, Racine-Poon A, Druker BJ, Talpaz M, et al. Pharmacokinetics and pharmacodynamics of imatinib in a phase I trial with chronic myeloid leukemia patients. J Clin Oncol (2004) 22(5):935-42. doi: 10.1200/JCO.2004.03.050

26. European Medicines Agency. Scientific Discussion on Tasigna, INN-Nilotinib (2007). Available from: http://www.ema.europa.eu/docs/en_GB/document_ library/EPAR_-_Scientific_Discussion/human/000798/WC500034398.pdf (Accessed May 25, 2018).
27. European Medicines Agency. ANNEX I. Summary of product characteristics, Iclusig, INN-ponatinib. (2013). Available at: http://www.ema.europa.eu/docs/ en_GB/document_library/EPAR_-_Product_Information/human/002695/ WC500145646.pdf (Accessed May 25, 2018).

28. FDA. (2012). Clinical Pharmacology and biopharmaceutics review(s). Available at: https://www.accessdata.fda.gov/drugsatfda_docs/nda/2012/2034 69Orig1s000ClinPharmR.pdf (Accessed May 25, 2018).

29. Tan SY, Kan E, Lim WY, Chay G, Law JH, Soo GW, et al. Metronidazole leads to enhanced uptake of imatinib in brain, liver and kidney without affecting its plasma pharmacokinetics in mice. J Pharm Pharmacol (2011) 63(7):918-25. doi: 10.1111/j.2042-7158.2011.01296.x

30. Gottardi M, Manzato E, Gherlinzoni F. Imatinib and hyperlipidemia. N Engl J Med (2005) 353(25):2722-3. doi: 10.1056/NEJMc052500

31. Franceschino A, Tornaghi L, Benemacher V, Assouline S, Gambacorti-Passerini C. Alterations in creatine kinase, phosphate and lipid values in patients with chronic myeloid leukemia during treatment with imatinib. Haematologica (2008) 93(2):317-8. doi: 10.3324/haematol.11680

32. Gologan R, Constantinescu G, Georgescu D, Ostroveanu D, Vasilache D, Dobrea C, et al. Hypolipemiant besides antileukemic effect of imatinib mesylate. Leuk Res (2009) 33(9):1285-7. doi: 10.1016/j. leukres.2009.02.024

33. Hochhaus A, Saglio G, Hughes TP, Larson RA, Kim DW, Issaragrisil S, et al. Long-term benefits and risks of frontline nilotinib vs imatinib for chronic myeloid leukemia in chronic phase: 5 -year update of the randomized ENESTnd trial. Leukemia (2016) 30(5):1044-54. doi: 10.1038/leu.2016.5

34. Libby P. Inflammation in atherosclerosis. Arterioscler Thromb Vasc Biol (2012) 32(9):2045-51. doi: 10.1161/ATVBAHA.108.179705

35. Kühnast S, van der Hoorn JW, van den Hoek AM, Havekes LM, Liau G, Jukema JW, et al. Aliskiren inhibits atherosclerosis development and improves plaque stability in $\mathrm{APOE}^{\star} 3$ Leiden.CETP transgenic mice with or without treatment with atorvastatin. J Hypertens (2012) 30(1):107-16. doi: 10.1097/ HJH.0b013e32834ddd8e

36. Kühnast S, Louwe MC, Heemskerk MM, Pieterman EJ, van Klinken JB, van den Berg SA, et al. Niacin reduces atherosclerosis development in $\mathrm{APOE}^{\star} 3 \mathrm{Leiden}$. CETP mice mainly by reducing NonHDL-Cholesterol. PLoS One (2013) 8(6):e66467. doi: 10.1371/journal.pone.0066467

37. Rea D, Mirault T, Cluzeau T, Gautier JF, Guilhot F, Dombret H, et al. Early onset hypercholesterolemia induced by the 2nd-generation tyrosine kinase inhibitor nilotinib in patients with chronic phase-chronic myeloid leukemia. Haematologica (2014) 99(7):1197-203. doi: 10.3324/ haematol.2014.104075

38. Breccia M, Loglisci G, Cannella L, Serrao A, Colafigli G, Salaroli A, et al. Nilotinib therapy does not induce consistent modifications of cholesterol metabolism resulting in clinical consequences. Leuk Res (2011) 35(11):e215-6. doi: 10.1016/j.leukres.2011.07.026

39. Baroni S, Scribano D, Zuppi C, Pagano L, Leone G, Giardina B. Prognostic relevance of lipoprotein cholesterol levels in acute lymphocytic and nonlymphocytic leukemia. Acta Haematol (1996) 96(1):24-8. doi: $10.1159 / 000203710$

40. Boren J, Cascante M, Marin S, Comín-Anduix B, Centelles JJ, Lim S, et al. Gleevec (STI571) influences metabolic enzyme activities and glucose carbon flow toward nucleic acid and fatty acid synthesis in myeloid tumor cells. J Biol Chem (2001) 276(41):37747-53. doi: 10.1074/jbc.M105796200

41. Lassila M, Allen TJ, Cao Z, Thallas V, Jandeleit-Dahm KA, Candido R, et al. Imatinib attenuates diabetes-associated atherosclerosis. Arterioscler Thromb Vasc Biol (2004) 24(5):935-42. doi: 10.1161/01.ATV.0000124105. 39900.db

42. Ballinger ML, Osman N, Hashimura K, de Haan JB, Jandeleit-Dahm K, Allen $\mathrm{T}$, et al. Imatinib inhibits vascular smooth muscle proteoglycan synthesis and reduces LDL binding in vitro and aortic lipid deposition in vivo. J Cell Mol Med (2010) 14(6B):1408-18. doi: 10.1111/j.1582-4934.2009.00902.x

43. El-Agamy DS. Nilotinib attenuates endothelial dysfunction and liver damage in high-cholesterol-fed rabbits. Hum Exp Toxicol (2017) 36(11):1131-45. doi: $10.1177 / 0960327116681649$

44. Hadzijusufovic E, Albrecht-Schgoer K, Huber K, Hoermann G, Grebien F, Eisenwort G, et al. Nilotinib-induced vasculopathy: identification of vascular endothelial cells as a primary target site. Leukemia (2017) 31(11):2388-97. doi: 10.1038/leu.2017.245 
45. Alhawiti N, Burbury KL, Kwa FA, O'Malley CJ, Shuttleworth P, Alzard M, et al. The tyrosine kinase inhibitor, nilotinib potentiates a prothrombotic state. Thromb Res (2016) 145:54-64. doi: 10.1016/j.thromres.2016.07.019

46. Gover-Proaktor A, Granot G, Shapira S, Raz O, Pasvolsky O, Nagler $A$, et al. Ponatinib reduces viability, migration, and functionality of human endothelial cells. Leuk Lymphoma (2017) 58(6):1455-67. doi: 10.1080/10428194.2016.1239258

47. Kang Z, Ji Y, Zhang G, Qu Y, Zhang L, Jiang W. Ponatinib attenuates experimental pulmonary arterial hypertension by modulating Wnt signaling and vasohibin-2/ vasohibin-1. Life Sci (2016) 148:1-8. doi: 10.1016/j.lfs.2016.02.017

48. Loren CP, Aslan JE, Rigg RA, Nowak MS, Healy LD, Gruber A, et al. The BCR-ABL inhibitor ponatinib inhibits platelet immunoreceptor tyrosinebased activation motif (ITAM) signaling, platelet activation and aggregate formation under shear. Thromb Res (2015) 135(1):155-60. doi: 10.1016/j. thromres.2014.11.009

49. Xu Z, Lioi J, Mu J, Kamocka MM, Liu X, Chen DZ, et al. A multiscale model of venous thrombus formation with surface-mediated control of blood coagulation cascade. Biophys J (2010) 98(9):1723-32. doi: 10.1016/j. bpj.2009.12.4331

50. Hedner U. Recombinant factor VIIa: its background, development and clinical use. Curr Opin Hematol (2007) 14(3):225-9. doi: 10.1097/ MOH.0b013e3280dce57b

51. Elice F, Rodeghiero F. Hematologic malignancies and thrombosis. Thromb Res (2012) 129(3):360-6. doi: 10.1016/j.thromres.2011.11.034
52. Šimkovič M, Vodárek P, Motyčková M, Belada D, Vrbacký F, Žák P, et al. Venous thromboembolism in patients with chronic lymphocytic leukemia. Thromb Res (2015) 136(6):1082-6. doi: 10.1016/j.thromres.2015.05.010

53. Falanga A. Thrombophilia in cancer. Semin Thromb Hemost (2005) 31(1):10410. doi: $10.1055 / \mathrm{s}-2005-863812$

Conflict of Interest Statement: CK has ownership interests in 'Good Biomarker Sciences'. RG is an employee at Bristol-Meyers Squibb, New York, USA. WJ received research grants from and has spoken at (CME-accredited) meetings sponsored by Amgen, Astellas, Astra-Zeneca, Daiichi Sankyo, Lilly, MerckSchering-Plough, Pfizer, Roche, Sanofi-Aventis, the Netherlands Heart Foundation, the Interuniversity Cardiology Institute of the Netherlands, and the European Community Framework KP7 Program.

The remaining authors declare that the research was conducted in the absence of any commercial or financial relationships that could be constructed as a potential conflict of interest.

Copyright (C) 2018 Pouwer, Pieterman, Verschuren, Caspers, Kluft, Garcia, Aman, Jukema and Princen. This is an open-access article distributed under the terms of the Creative Commons Attribution License (CC BY). The use, distribution or reproduction in other forums is permitted, provided the original author(s) and the copyright owner are credited and that the original publication in this journal is cited, in accordance with accepted academic practice. No use, distribution or reproduction is permitted which does not comply with these terms. 